\title{
Apolipoprotein E Polymorphism and Dementia: A Hospital-Based Study from Southern India
}

\author{
Srikala Bharath $^{a} \quad$ Meera Purushottam $^{a}$ Odity Mukherjee $^{b}$ \\ Bhavani Shankara Bagepally $^{a}$ Om Prakash ${ }^{c} \quad$ Lakshminarayanan Kota $^{a}$ \\ Srinivas Brahmadevarahalli Krishnappa ${ }^{b}$ Palanimuthu Thangaraju Sivakumar ${ }^{a}$ \\ Sanjeev Jain ${ }^{a}$ Mathew Varghese ${ }^{a}$ \\ ${ }^{a}$ National Institute of Mental Health and Neurosciences, b National Center for Biological Sciences, Bangalore, and \\ 'Institute of Human Behavior and Allied Sciences, Delhi, India
}

\section{Key Words}

Dementia • Alzheimer's disease • Vascular dementia •

ApoE4 • India $\cdot$ Cognitive disorders $\cdot$ Geriatric clinic

\begin{abstract}
Background/Aims: To evaluate the ApoE gene polymorphism among patients with dementia from southern India. Methods: Persons with dementia attending a geriatric clinic in a hospital setting located in southern India and matched controls were recruited. All subjects were evaluated on standard assessments and were diagnosed according to the ICD10; genotyping was done at the apolipoprotein E (ApoE) locus. Results: The study comprised 212 cases and 195 controls. The ApoE4 allele was significantly more prevalent in dementia ( $\lambda=0.18$ vs. $\lambda=0.07 ; p=0.0018$ ), especially in the Alzheimer's disease subgroup $(n=137 ; \lambda=0.21$ vs. $\lambda=0.07$; $p<0.001)$, with a trend in vascular dementia subtype $(n=31$; $\lambda=0.17$ vs. $\lambda=0.07$ ) in comparison with the control group. ApoE4 carrier status did not differ between the other dementia group $(n=44)$ and controls $(p>0.20)$, or between the Alzheimer's group and vascular dementia groups. Cognitive
\end{abstract}

\section{KARGER}

Fax +4161306 1234

E-Mail karger@karger.ch

www.karger.com
(C) 2011 S. Karger AG, Basel

$1420-8008 / 10 / 0306-0455 \$ 26.00 / 0$

Accessible online at: www.karger.com/dem and functional deficits were not correlated to the presence ApoE4 polymorphism in the dementia group. Conclusion: The study confirmed the positive association of the ApoE4 polymorphism in dementia, both in the Alzheimer's and vascular etiology subgroups. Influence of this polymorphism on various clinical phenotypes, including extent of cognitive and functional deficits, needs further evaluation.

Copyright $\odot 2011$ S. Karger AG, Basel

\section{Background}

Apolipoprotein E (ApoE) is one of the most extensively studied genes in dementia [1]. The ApoE4 allele was initially identified as a 'risk factor' for Alzheimer's disease (AD), and later with other types of dementias like vascular dementia $(\mathrm{VaD})$ [2] and frontotemporal dementia (FTD) [3]. ApoE4 is also a 'risk factor' for other age- and lifestyle-related conditions like diabetes [4], atherosclerosis, hyperlipidemia and cardiovascular conditions [2], which in turn are risk factors for neurodegeneration. Thus, the ApoE4 allele seems to increase the risk for AD 
and $\mathrm{VaD}$, both directly and indirectly through other risk factors $[5,6]$. The association of ApoE4 and dementia is variable across different populations/geographical locations of the world $[7,8]$. For instance, the association of ApoE4 and dementia is high among populations of European origin, but low in Africans and Japanese [7].

India is a geographically vast country with a diverse population in terms of language, race and ethnicity. Though the ApoE4 frequency and dementia is lower in India in comparison to Western populations, the positive association of ApoE4 is confirmed in epidemiologic- and clinic-based samples [2, 7]. There is published work from northern India on ApoE gene polymorphism and dementia $[2,7,9,10]$, but there is no published work on this aspect from southern India [11]. ApoE polymorphism in dementia from a hospital setting in Bangalore (southern India) is reported here.

\section{Methods}

Sample

The study sample included all consenting patients with dementia $(\mathrm{PwD} ; \mathrm{n}=212)$ attending the geriatric clinic of the $\mathrm{Na}$ tional Institute of Mental Health and Neurosciences (NIMHANS) located in southern India. The controls $(n=195)$ were age- and gender-matched healthy elderly persons who consented to participate in the study.

All patients underwent detailed neuropsychiatric evaluation by trained psychiatric residents. Cognitive functions were assessed with the Hindi Mental State Examination (HMSE) [12], the Indian adaptation of the Mini-Mental Status Examination [13]. Activities of daily living were assessed with Everyday Abilities Scales India (EASI) [14]. They were later interviewed by one of the psychiatric consultants and a diagnosis was made. In cases of diagnostic discrepancy, opinion was sought with another consultant and a liaison neurologist, after which consensus was reached. Diagnosis was made according to International Classification of Disease-10 [15]. The categories used were AD (F00); VaD (F01), including mixed dementia; dementia in other diseases classified elsewhere (F02), including FTD and dementia of Lewy body disease (DLBD); and unspecified dementia (F03). The consultant assessed the severity of dementia with the Clinical Dementia Rating Scale [16]. The controls were also evaluated with HMSE and EASI. Ten milliliters of venous blood was collected from patients and healthy controls after informed consent was obtained.

The subjects were recruited from 2001 to 2009 as part of ongoing research in the clinic. The institutional ethics committee of NIMHANS approved all the research protocols.

\section{Genotyping at the ApoE Locus}

From the collected blood samples, high-molecular weight genomic DNA was isolated using the modified salting-out protocol [17]. Polymerase chain reaction (PCR) amplification was performed using gene specific primers (forward: $5^{\prime}$-TAA GCT TGG CAC GGC TGT CCA AGG A-3', reverse: 5'-ACA GAA TTC GCC
CCG GCC TGG TAC ACT GCC-3') followed by restriction enzyme cleavage of the PCR products with the HhaI enzyme to generate allele-discriminating DNA fragments [18]. Briefly, the 3 alleles E2, E3 and E4 defined by the presence of either C or T nucleotides at codons 112 and 158 in the 4th exon of the ApoE gene was determined by the PCR restriction fragment length polymorphism method.

\section{Statistical Methods}

Statistical analysis was done using R software (http://www.Rproject.org). For the purpose of analysis, $\mathrm{PwD}$ were grouped into $\mathrm{AD}$, dementia with vascular etiology (VaD and mixed dementia) and other dementia (FTD, DLBD, etc.). Comparisons between the groups on categorical variables were made with Pearson's 2-tailed $\chi^{2}$ test. Student's t test was used for comparisons involving continuous variables. Bonferroni correction (BC) was applied for multiple comparisons. Statistical significance was noted at $\mathrm{p}<$ 0.05 . Pearson's 2 -sided product-moment correlation test was used for correlation. The odds ratio (OR) was calculated.

\section{Results}

The sample consisted of 137 patients with AD, 31 patients with dementia of a vascular etiology $(\mathrm{VaD})$ and 44 patients with other dementia (FTD: 25, DLBD: 15, undifferentiated: 4). There was no difference in age and gender between the study groups, or among/between the subgroups of dementia and controls. There was no significant difference in the cognitive impairment, dysfunction in activities of daily life and severity of dementia between the subgroups of dementia as measured by HMSE, EASI or Clinical Dementia Rating scores (table 1).

The distribution of alleles at the ApoE4 locus was in Hardy-Weinberg equilibrium [19]. ApoE 33 was the most common genotype both among $\mathrm{PwD}$ (59.9\%) and healthy controls (72.3\%), followed by other types of ApoE (table 2),

The ApoE allele frequencies in the $\mathrm{PwD}$ were 0.07 , 0.75 and 0.18 for ApoE2, ApoE3 and ApoE4, respectively, in comparison to $0.08,0.84$ and 0.08 , respectively, in the control population. The frequency of ApoE4 allele was significantly more in the $\mathrm{PwD}$ group as a whole $(\mathrm{BC} \mathrm{p}=$ $0.0018)$ and the $\mathrm{AD}$ group $(\mathrm{BC} \mathrm{p}<0.001)$ than the healthy controls. There was no significant difference in the ApoE4 frequency $(\mathrm{BC} \mathrm{p}=0.10)$ between the $\mathrm{VaD}$ group and healthy controls, though there was a trend towards higher ApoE4 in $\mathrm{VaD}$ (uncorrected $\mathrm{p}=0.017$ ). Frequency of ApoE4 was significantly more in the $\mathrm{AD}$ group (BC $\mathrm{p}=0.006)$ in comparison to the other dementia group (FTD, DLBD, etc.). There was also a trend towards significance of the ApoE4 frequency in the $\mathrm{VaD}$ group in comparison to the other dementia group (uncorrected 
Table 1. Sociodemographic and clinical data of the subjects

\begin{tabular}{|c|c|c|c|c|c|}
\hline & $\begin{array}{l}\text { All dementia } \\
(\mathrm{n}=212)\end{array}$ & $\begin{array}{l}\mathrm{AD} \\
(\mathrm{n}=137)\end{array}$ & $\begin{array}{l}\mathrm{VaD}+\mathrm{MD} \\
(\mathrm{n}=31)\end{array}$ & $\begin{array}{l}\text { Other dementia } \\
(\mathrm{n}=44)\end{array}$ & $\begin{array}{l}\text { Controls } \\
(\mathrm{n}=195)\end{array}$ \\
\hline Age, years & $66.6 \pm 9.1$ & $67.5 \pm 8.3$ & $68.5 \pm 9.7$ & $62.4 \pm 10.4$ & $64.8 \pm 7.7$ \\
\hline ApoE4, positive:negative & $70: 142$ & $54: 83$ & $10: 21$ & $6: 38$ & $29: 166$ \\
\hline Duration of illness, months & $31.4 \pm 24$ & $32.7 \pm 22.6$ & $30.2 \pm 26.3$ & $28.5 \pm 22.6$ & not applicable \\
\hline HMSE & $12 \pm 8.6$ & $12 \pm 8.2$ & $12.2 \pm 9.0$ & $11.8 \pm 9.7$ & $30.4 \pm 0.9$ \\
\hline CDR & $2 \pm 0.6$ & $2 \pm 0.7$ & $2 \pm 0.6$ & $2 \pm 0.7$ & 0 \\
\hline
\end{tabular}

$\mathrm{CDR}=$ Clinical dementia rating scale; $\mathrm{MD}=$ mixed dementia.

Table 2. ApoE allele frequencies in subjects

\begin{tabular}{|c|c|c|c|c|c|c|c|c|c|}
\hline Allele & ApoE2 & ApoE3 & ApoE4 & ApoE2 2 & ApoE2 3 & ApoE2 4 & ApoE3 3 & ApoE3 4 & ApoE4 4 \\
\hline Controls $(n=195)$ & 0.0794 & 0.841 & 0.0794 & 1 & 24 & 5 & 141 & 22 & 2 \\
\hline Dementia $(n=212)$ & 0.0731 & 0.7476 & 0.1792 & 1 & 14 & 15 & 127 & 49 & 6 \\
\hline $\mathrm{VaD}$ and mixed dementia $(\mathrm{n}=31)$ & 0.0484 & 0.7742 & 0.1774 & - & 1 & 2 & 20 & 7 & 1 \\
\hline Other dementia $(\mathrm{n}=44)$ & 0.0568 & 0.8636 & 0.0795 & 1 & 3 & 0 & 34 & 5 & 1 \\
\hline
\end{tabular}

Table 3. Comparison of ApoE4 frequencies between the subtypes of dementia

\begin{tabular}{|c|c|c|c|c|}
\hline Group 1 & Group 2 & $\begin{array}{l}\mathrm{p} \text { value } \\
\text { uncorrected }\end{array}$ & $\begin{array}{l}\text { Bonferroni } \\
\text { corrected p value }\end{array}$ & $\begin{array}{l}\text { OR } \\
(95 \% \mathrm{CI})\end{array}$ \\
\hline All dementia $(\mathrm{n}=212)$ & controls $(\mathrm{n}=195)$ & $<0.001^{*}$ & $0.0018^{* *}$ & $2.82(1.73-4.59)$ \\
\hline $\mathrm{VaD}+\mathrm{MD}(\mathrm{n}=31)$ & controls $(\mathrm{n}=195)$ & $0.017^{*}$ & 0.10 & $2.73(1.16-6.38)$ \\
\hline Other dementia $(\mathrm{n}=44)$ & controls $(n=195)$ & 0.834 & 5.004 & $0.90(0.35-2.33)$ \\
\hline $\mathrm{AD}(\mathrm{n}=137)$ & $\mathrm{VaD}+\mathrm{MD}(\mathrm{n}=31)$ & 0.459 & 2.754 & $1.36(0.59-3.13)$ \\
\hline $\mathrm{VaD}+\mathrm{MD}(\mathrm{n}=31)$ & other dementia $(n=44)$ & 0.053 & 0.318 & $3.02(0.96-9.47)$ \\
\hline
\end{tabular}

${ }^{*}$ Uncorrected $\mathrm{p}$ values significant at $<0.05 ;{ }^{*}$ Bonferroni corrected $\mathrm{p}$ values significant at $<0.05$. MD $=$ Mixed dementia.

$\mathrm{p}=0.05)$. The frequency of ApoE4 between the $\mathrm{AD}$ and $\mathrm{VaD}$ was not different $(\mathrm{BC} \mathrm{p}=2.75)$; the same was true between the other dementia group and healthy controls $(\mathrm{BC} \mathrm{p}=5.00)$

The risk of dementia, both $\mathrm{AD}$ and $\mathrm{VaD}$, in those with an ApoE4 allele was 3-4 times higher (OR: 2.72 in VaD and 3.72 in $\mathrm{AD}$ ) (table 3). ApoE4 status did not influence the age of onset of dementia ( $p>0.05)$, severity of cognitive impairment or functional disabilities among the PwD (HMSE = ApoE4-positive: $14.79 \pm 9.24$ vs. ApoE4negative: $16.43 \pm 11.34$, F value: $1.519, \mathrm{p}=0.219,95 \% \mathrm{CI}$ : 9.94-13.03; and EASI = ApoE4-positive: $6.69 \pm 3.56$ vs. ApoE4-negative: $5.95 \pm 4.4$, F value: $1.770, \mathrm{p}=0.185,95 \%$ CI: -1.85 to 0.36 ). 
Table 4. Summary of earlier reports of ApoE in dementia from India

\begin{tabular}{|c|c|c|c|c|c|}
\hline Study & Subjects & ApoE2 & ApoE3 & ApoE4 & Location \\
\hline Singh et al., 2006 [8] & $\begin{array}{l}\text { Sikhs }(\mathrm{n}=109) \\
\text { Hindus }(\mathrm{n}=114) \\
\text { Maria Gond }(\mathrm{n}=149) \\
\text { Koch }(\mathrm{n}=125)\end{array}$ & $\begin{array}{l}0.050 \\
0.061 \\
0.094 \\
0.032\end{array}$ & $\begin{array}{l}0.876 \\
0.851 \\
0.876 \\
0.968\end{array}$ & $\begin{array}{l}0.074 \\
0.088 \\
0.030 \\
0.000\end{array}$ & $\begin{array}{l}\text { general population Punjab, } \\
\text { North India }\end{array}$ \\
\hline Singh et al., 2001 [27] & $\begin{array}{l}\mathrm{n}=80 \\
\mathrm{n}=70\end{array}$ & $\begin{array}{l}0.031 \\
0.043\end{array}$ & $\begin{array}{l}0.913 \\
0.886\end{array}$ & $\begin{array}{l}0.056 \\
0.071\end{array}$ & Ramgarhia, Punjab, North India \\
\hline $\begin{array}{l}\text { ApoE Frequencies in Demer } \\
\text { Ganguli et al., } 2000 \text { [7] } \\
\text { (epidemiological study) }\end{array}$ & age $55-95$ years $(n=4,450)$ & 0.039 & 0.887 & 0.073 & Ballabgarh, North India \\
\hline Luthra et al., 2004 [2] & $\begin{array}{l}\mathrm{AD}(\mathrm{n}=29) \\
\operatorname{VaD}(\mathrm{n}=25) \\
\text { controls }(\mathrm{n}=76)\end{array}$ & $\begin{array}{l}0.086 \\
0.080 \\
0.145\end{array}$ & $\begin{array}{l}0.621 \\
0.580 \\
0.763\end{array}$ & $\begin{array}{l}0.293 \\
0.340 \\
0.09\end{array}$ & hospital-based, North India \\
\hline Kaur and Balgir, 2005 [22] & $\begin{array}{l}\text { AD consanguineous }(n=26) \\
\text { AD nonconsanguineous }(n=76) \\
\text { spouses of } \mathrm{AD}(\mathrm{n}=36)\end{array}$ & $\begin{array}{l}0.07 \\
0.09\end{array}$ & $\begin{array}{l}0.41 \\
0.46 \\
0.78\end{array}$ & $\begin{array}{l}0.5 \\
0.47 \\
0.13\end{array}$ & $\begin{array}{l}\text { Department of Biotechnology, } \\
\text { Punjabi University, Patiala }\end{array}$ \\
\hline Kapur et al., 2006 [10] & $\begin{array}{l}\mathrm{AD}(\mathrm{n}=14) \\
\text { first-degree relatives of } \mathrm{AD}(\mathrm{n}=6) \\
\text { controls (not age-matched; } \mathrm{n}=46)\end{array}$ & $\begin{array}{l}0.22 \\
0.34 \\
0.27\end{array}$ & $\begin{array}{l}0.36 \\
0.33 \\
0.62\end{array}$ & $\begin{array}{l}0.43 \\
0.34 \\
0.11\end{array}$ & $\begin{array}{l}\text { hospital-based sample } \\
\text { (from IHBAS Delhi, India) }\end{array}$ \\
\hline Chandak et al., 2002 [30] & $\begin{array}{l}\mathrm{AD}(\mathrm{n}=49) \\
\operatorname{VaD}(\mathrm{n}=12) \\
(\mathrm{AD}+\operatorname{VD})(\mathrm{n}=10) \\
\text { control }(\mathrm{n}=100)\end{array}$ & $\begin{array}{l}0.03 \\
- \\
- \\
0.03\end{array}$ & $\begin{array}{l}0.78 \\
0.92 \\
0.75 \\
0.88\end{array}$ & $\begin{array}{l}0.19 \\
0.08 \\
0.25 \\
0.085\end{array}$ & $\begin{array}{l}\text { part of larger epidemiologic } \\
\text { study from a suburb of Mumbai }\end{array}$ \\
\hline
\end{tabular}

\section{Discussion}

This study confirms the work of different groups in India pertaining to $\mathrm{ApoE} 4$ in dementia, $\mathrm{AD}$ and $\mathrm{VaD}$ in particular (table 4). Firstly, it reiterates the low frequency (0.07) of ApoE4 in the Indian population. Other Indian studies have quoted an ApoE4 frequency range of 0.00 (specific communities) [20] to 0.09 [2]. The epidemiological study from Ballabgarh [7], the largest in the country $(\mathrm{n}=4,450)$, reported a frequency of 0.07 for ApoE 4 in their cohort, which is same as in the present work.

Secondly, the current clinic-based study from southern India confirms the increased frequency of ApoE4 in PwD (0.18), especially in AD (0.21). The frequency was higher than the community-based study from Ballabgarh [7] (0.15 in all dementias), and the hospital-based study from Lucknow (0.13) [21], but less than the other hospitalbased studies of New Delhi (0.29-0.43) [2, 10, 22].
The study also concurs with other Indian studies - that the risk for dementia, especially $\mathrm{AD}$, increases significantly with the ApoE4 allele [2, 7, 21, 22]. For example, despite having a low frequency of ApoE4 in the cohort, the Ballabgarh study [7] found that those with the ApoE4 allele were 2.6 to 3.4 times associated with $\mathrm{AD}$ [7].

Other than the AD group, there was an increased frequency of the ApoE4 allele in the VaD group in this study $(\lambda=0.17)$. Two groups from northern India have reported an increased frequency of ApoE4 in $\mathrm{VaD}$ in comparison to the controls [2, 21]. Luthra et al. [2] from New Delhi reported a frequency of ApoE 4 in $\mathrm{VaD}(0.34)$ higher than in $\mathrm{AD}(0.29)$. Although the sociodemographic data, assessment measures and frequency of hypertension in $\mathrm{VaD}(61-68 \%)$ were similar to our study, the diagnostic criteria for subtyping was different; the current study used ICD-10, while Luthra et al. [2] used NINCDS criteria. The same investigators had previously reported an association between stroke and the ApoE4 allele [23]. The 
Fig. 1. Scatter plot showing the inverse relationship between HMSE and EASI.

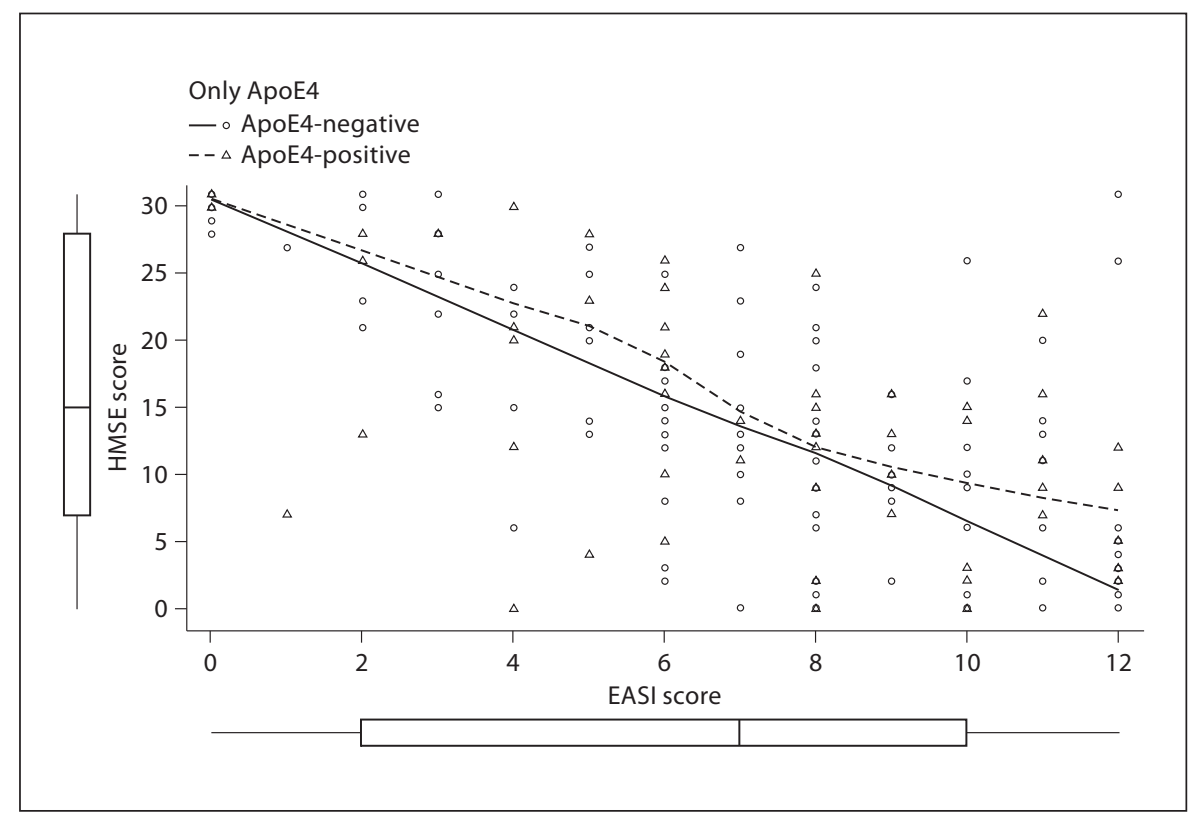

direct and indirect contributions of ApoE4 distribution on $\mathrm{VaD}$ are beyond the scope of this paper; however, they require further work as cardiovascular diseases are projected by the World Health Organization to be one of the leading chronic illnesses in India, predicted to account for $28 \%$ in the future (http://www.who.int/ chp/chronic diseases_report_en/).

There was no difference in the age of onset, cognitive functions and activities of daily living among the dementia subjects with and without the ApoE4 allele (fig. 1). While research from the West has shown otherwise with more impairment in ApoE4 carriers [24-26], many Indian studies $[2,7,10,21,22]$ have not commented on the relationship between ApoE4, extent of cognitive decline or subtype of dementia.

There was no increased frequency of ApoE4 among other dementias like FTD and DLBD, which have been reported by a few in the West $[3,27]$.

All the Indian studies quoted above and the current work used different, but standard instruments to assess cognitive deficits (Mini-Mental Status Examination, HMSE), activities of daily living (EASI, IADL) and diagnostic criteria (ICD 10, NINCDS, DSM IV) and, hence, are comparable, as are the results pertaining to ApoE4 frequency in $\mathrm{PwD}$.

Population diversity is known to influence ApoE4 frequency in the general population $[8,27]$ and in dementia $[7,28,29]$. However, ApoE4 frequency in the control samples from northern and southern India are broadly similar, and are also close to the frequencies reported from the Middle East and Eastern Europe [8]. ApoE4 levels in Western Europe seem to be higher in the general population. Thus, although the positive association between risk of dementia and ApoE4 are confirmed in all these populations, the contributions to this risk could vary depending upon the allele frequency, presence of other susceptibility or interacting risk factors (genetic risks for diabetes and vascular disease) and environmental factors (malnutrition, infectious disease, etc.). As the demographic pyramid in the Indian population is likely to change over the next few years, it will be useful to study the interaction between these factors to better understand the pathways between genetic risk and final disease pathobiology. The present work with limited cognitive assessment of the PwD did not confirm the association of ApoE4 and severity of cognitive deficits. This indicates the need for further longitudinal work to correlate the plethora of clinical phenotypes to the genotypes of dementias in India.

The smaller size of the $\mathrm{VaD}$ group, heterogeneity among that group, lack of imaging studies and detailed neuropsychological assessment for all $\mathrm{PwD}$ are some of the limitations of the study. Our geriatric group from NIMHANS is working towards addressing these deficits and making the assessments comprehensive. 
In conclusion, this study from southern India supplements work from other parts of the country on ApoE genetic polymorphism both in healthy individuals and PwD. It confirms the 'risk status' of ApoE4 in AD, but not in other dementias. It also indicates the need for more work in $\mathrm{VaD}$ and ApoE4 in the Indian context.

\section{Acknowledgements}

The study was supported by grants received from Department of Biotechnology, India Indian Council of Medical Research, India. We would like to thank Dr. Thennarasu, Department of Biostatistics, for suggestions on statistical analysis.

\section{References}

1 Farrer L, Cupples L, Haines J, et al: Effects of age, sex, and ethnicity on the association between apolipoprotein $\mathrm{E}$ genotype and $\mathrm{Alz}$ heimer disease: a meta-analysis. APOE and Alzheimer's Disease Analysis Consortium. JAMA 1997;278:1349-1356.

-2 Luthra K, Tripathi M, Grover R, Dwivedi M, Kumar A, Dey A: Apolipoprotein E gene polymorphism in Indian patients with $\mathrm{Alz}$ heimer's disease and vascular dementia. Dement Geriatr Cogn Disorder 2004;17:132135.

3 Agosta F, Vossel KA, Miller BL, et al: Apolipoprotein E e4 is associated with diseasespecific effects on brain atrophy in Alzheimer's disease and frontotemporal dementia. PNAS 2009; 106:2018-2022.

4 Peila R, Rodriguez BL, Launer LJ: Type 2 diabetes, APOE gene, and the risk for dementia and related pathologies: the Honolulu-Asia Aging Study. Diabetes 2002;51:1256-1262.

5 Haan MN, Aiello AE, West NA, Jagust WJ: $\mathrm{C}$-reactive protein and rate of dementia in carriers and non carriers of Apolipoprotein APOE4 genotype. Neurobiol Aging 2009;29: 1774-1782.

6 Kivipelto M, Helkala E, Laakso MP, et al: Apolipoprotein E4 allele, elevated midlife total cholesterol level, and high midlife systolic blood pressure are independent risk factors for late-life Alzheimer disease. Ann Intern Med 2002;137:149-155.

-7 Ganguli M, Chandra V, Kamboh MI, et al: Apolipoprotein E polymorphism and Alzheimer disease. Arch Neurol 2000;57:824830.

8 Singh PP, Singh M, Mastana SS: APOE distribution in world populations with new data from India and the UK. Ann Hum Biol 2006; 33:279-308

$\checkmark 9$ Mastana S, Calderon R, Pena J, Reddy P, Papiha S: Anthroplogy of the apolipoprotein $\mathrm{E}$ (apoe E) gene: low frequency of apo E4 allele in Basques and in tribal (Baiga) populations of India. Ann Hum Biol 1998;25:137-143.
10 Kapur S, Sharad S, Kapoor M, Bala K: ApoE genotypes: risk factor for Alzheimer's disease. J Indian Acad Clin Med 2006;7:118122.

11 Reich D, Thangaraj K, Patterson N, Price AL, Singh L: Reconstructing Indian population history. Nature 2009;461:489-494.

12 Ganguli M, Chandra V, Sharma S, et al: A Hindi version of the MMSE: the development of a cognitive screening instrument for a largely illiterate rural elderly population in India. Int J Geriatr Psychiatry 1995;10:367377.

13 Folstein MF, Folstein SE, McHugh PR: 'Mini-mental state': a practical method for grading the cognitive state of patients for the clinician. J Psychiatr Res 1975;12:189-198.

14 Fillenbaum GG, Chandra V, Ganguli M, et al: Development of an activities of daily living scale to screen for dementia in an illiterate rural older population in India. Age Ageing 1999;28;161-168.

15 The ICD-10 Classification of Mental and Behavioural Disorders. Clinical Descriptions and Diagnostic Guidelines. Geneva, World Health Organization, 1992.

16 Morris JC: The Clinical Dementia Rating (CDR): current version and scoring rules. Neurology 1993;43:2412-2414.

17 Miller S, Dykes D, Polesky H: A simple salting out procedure for extracting DNA from human nucleated cells. Nucleic Acids Res 1988; 16:1215

18 Wenham PR, Price WH, Blundell G: Apolipoprotein E genotyping by one-stage PCR. Lancet 1991;337:1158-1159.

19 Rodriguez S, Gaunt TR, Day IN: HardyWeinberg equilibrium testing of biological ascertainment for Mendelian randomization studies. Am J Epidemiol 2009;169:505514.

20 Singh PP, Singh M, Mastana SS: APOE distribution in world populations with new data from India and the UK. Hum Dev 2006;33: 279-308.
21 Pandey P, Pradhan S, Mittal B: Presenilin gene predisposes to late-onset degenerative but not vascular dementia: comparative study of PS1 and ApoE genes in a North Indian Cohort. Dement Geriatr Cogn Disord 2007;24:151-161.

22 Kaur M, Balgir P: APOE2 and consanguinity: a risky combination for Alzheimer's disease. J Alzheimer Dis 2005;8:893-897.

23 Luthra K, Bharghav B, Chabbra S, et al: Apolipoprotein E polymorphism in Northern Indian patients with coronary heart disease: phenotype distribution and relation to serum lipids and lipoproteins. Mol Cell Biochem 2002;232:97-102.

24 Raber J, Huang Y, Ashford JW: ApoE genotype accounts for the vast majority of $\mathrm{AD}$ risk and $\mathrm{AD}$ pathology. Neurobiol Aging 2004;25:641-650.

25 Henderson AS, Jorm AF, Korten AE, et al: Apolipoprotein E allele 4, dementia, and cognitive decline in a population sample. Lancet 1995;346:1387-1390.

26 Bookheimer S, Burggren A: APOE-4 genotype and neurophysiological vulnerability to Alzheimer's and cognitive aging. Ann Rev Clin Psychol 2009;5:343-362.

27 Singh P, Singh M, Gerdes UMS: Apolipoprotein $\mathrm{E}$ polymorphism in India: high $\mathrm{APOE}^{*} \mathrm{E} 3$ allele frequency in Ramgarhia of Punjab. Anthropol Anz 2001;59:27-34.

28 Sink KM, Covinsky KE, Newcomer R, Yaffe $\mathrm{K}$ : Ethnic differences in the prevalence and pattern of dementia-related behaviors. J Am Geriatr Soc 2004;52:1277-1283.

29 Demirovic J, Prineas R, Loewenstein D, et al: Prevalence of dementia in three ethnic groups: the South Florida Program on Aging and Health. Ann Epidemiol 2003;13:472478

30 Chandak GR, Sridevi MU, Vas CJ, Panikker DM, Singh L: Apolipoprotein E and presenilin-1 allelic variation and Alzheimer's disease in India. Hum Biol 2002;74:683-693. 